Article

\title{
Evaluation of the Equity of Urban Park Green Space Based on Population Data Spatialization: A Case Study of a Central Area of Wuhan, China
}

\author{
Chuandong Tan ${ }^{\dagger}$, Yuhan Tang ${ }^{\dagger}$ and Xuefei $\mathrm{Wu}^{*}$ \\ Department of Landscape Architecture, College of Horticulture and Forestry, Huazhong Agricultural University, \\ No. 1, Shizishan Street, Hongshan District, Wuhan 430070, China \\ * Correspondence: wuxf@mail.hzau.edu.cn; Tel.: +86-130-7127-2227 \\ + These authors contributed equally to this work and should be considered co-first authors.
}

Received: 1 May 2019; Accepted: 30 June 2019; Published: 2 July 2019

\begin{abstract}
To measure the equity of urban park green space, spatial matching between service supply and user group demand should be taken into consideration. However, if the demographic data, with the administrative division as the basic unit, are directly applied to characterize the spatial distribution of a user group, it may introduce inevitable deviation into the evaluation results due to the low-resolution nature and modifiable areal unit problem of such data. Taking the central area of Wuhan as an example, the population data spatialization method based on land use modeling was used to build a geographically weighted regression (GWR) model of land cover type and demographic data, and the spatial distribution of the population of the $150 \mathrm{~m}$ grid was obtained by inversion. Then, the equity of park green space in Wuhan central city was evaluated by population spatial data and network accessibility. The results showed that (1) the range of park green space in the central urban area of Wuhan was within a walking distance of $15 \mathrm{~min}$, accounting for $25.8 \%$ of the total study area and covering $54.2 \%$ of the population in the study area; (2) the equity of park green space in Hongshan District was the worst; (3) and the use of population spatial data can measure equity on a more precise scale.
\end{abstract}

Keywords: urban park green space; accessibility; equity; population data spatialization

\section{Introduction}

As a key component of urban green infrastructure, the urban park green space can not only provide a series of ecosystem services such as stormwater management [1], heat regulation [2], and air purification [3], but also has many social-economic benefits, such as increasing neighborhood communication [4], providing natural leisure experience [5], promoting physical and mental health [6], and boosting real estate prices [7]. Therefore, the reasonable distribution of the park green space is of great significance for enhancing the overall well-being of urban dwellers [8]. However, with the acceleration of urbanization, park green space resources in most cities are hardly meeting the needs of rapid population expansion, and the phenomenon of the uneven distribution of park green spaces has received particular attention $[9,10]$.

The study of the equity of urban park green spaces has gone through a development from quantitative equalization to spatial equity and finally formed social aspects. The early studies paid more attention to the quantity aspect of equity, such as the per capita green area, the green space rate, the greening coverage rate, and so on, which are still the official evaluation indexes in the current urban green space planning system in China. This method has some limitations, such as ignoring the spatial equity of green space layout, ecosystem service function, and resource sharing. With the 
concept of the accessibility and development of Geographic Information System (GIS) technology, increasingly, scholars have begun to pay attention to spatial distribution in the research into the equity of urban parks [11]. Accessibility analysis has also been widely used in spatial distribution studies of other important public service facilities in cities, such as health care services [12,13], shopping service centers [14] and sports facilities [15]. Accessibility only considers the opportunity and distance of individuals using park green space and thus is regarded as a kind of spatial equity. However, social equity places an emphasis on equal public services for all urban dwellers and focuses more on the satisfaction of the needs of special groups with limited mobility or with low socioeconomic status, including children, the elderly, low-income people, and ethnic minority people $[10,16]$. Therefore, in order to realize the social equity of the distribution of urban park green space, it is necessary to consider the spatial distribution of the needs of the users, thus reflecting the spatial match between the public services provided by the park and the users.

Evaluating the equity of public services should measure the spatial and quantitative relationship between user demand and object supply. When we evaluate urban park equity, the supply and demand are generally represented by park accessibility and population density, respectively [17]. Moreover, most of the relevant studies are carried out directly using census data $[1,9,10]$ and assume that the population is evenly distributed within the statistical unit. However, there are some limitations to this assumption because of the spatial heterogeneity of population distribution. The direct use of population data based on administrative division statistics in micro and medium-scale urban research makes it difficult to meet the corresponding precision requirements, and there is a modifiable areal unit problem [18], which means the analysis results are affected by the selected analysis area unit. In order to improve the accuracy of the evaluation, some studies directly use building data or residential committee data [19-21] to characterize population distribution. However, such data is often difficult to obtain. Therefore, this study introduces a population data spatialization method to obtain a more accurate spatial distribution of population, thus exploring a more universal and finer spatial-scale evaluation method of park equity.

Consequently, the aim of this study is to evaluate the equity of urban park green spaces in a finer spatial scale by using the population spatialization data. We choose Wuhan as our case study and focus on distributional equity in terms of equal access to urban park green spaces across all social groups. By constructing a regression model between the land cover and the statistical population, the grid map of the high-precision population distribution of Wuhan central area is obtained, and the corresponding population demand is measured. Moreover, the accessibility analysis of the parks was evaluated quantitatively by using the ArcGIS Network analysis tools, and the spatial superposition analysis method is used to analyze the spatial equity of the urban park green spaces in the study area.

\section{Study Area and Data Sources}

\subsection{Study Area}

Located in the heart of China's hinterland, as the capital of Hubei province, Wuhan is the central city of the country central part. The Yangtze River and the Han River meet in the center of Wuhan. Rich in water resources, Wuhan has 140 rivers with a length of more than $5 \mathrm{~km}$. Also, Wuhan contains 273 types of reservoirs and 166 lakes, of which 38 are in the central city.

Wuhan is under the jurisdiction of 13 administrative districts (including 7 central urban districts and 5 surrounding urban districts) and 4 development zones. The scope of this study includes the central areas of Wuhan City (Figure 1), which include Jiang'an, Jianghan, Qiaokou, Hanyang, Wuchang, Hongshan. and Qingshan. The plant area of WISCO (Wuhan Iron \& Steel Co Ltd.) is excluded from the research scope due to the lack of data. Consisting of 89 streets, the study area is $628 \mathrm{~km}^{2}$ (including $28.9 \mathrm{~km}^{2}$ of green park) with a population of 5.726 million, and the average population density is 9118 per $\mathrm{km}^{2}$. 


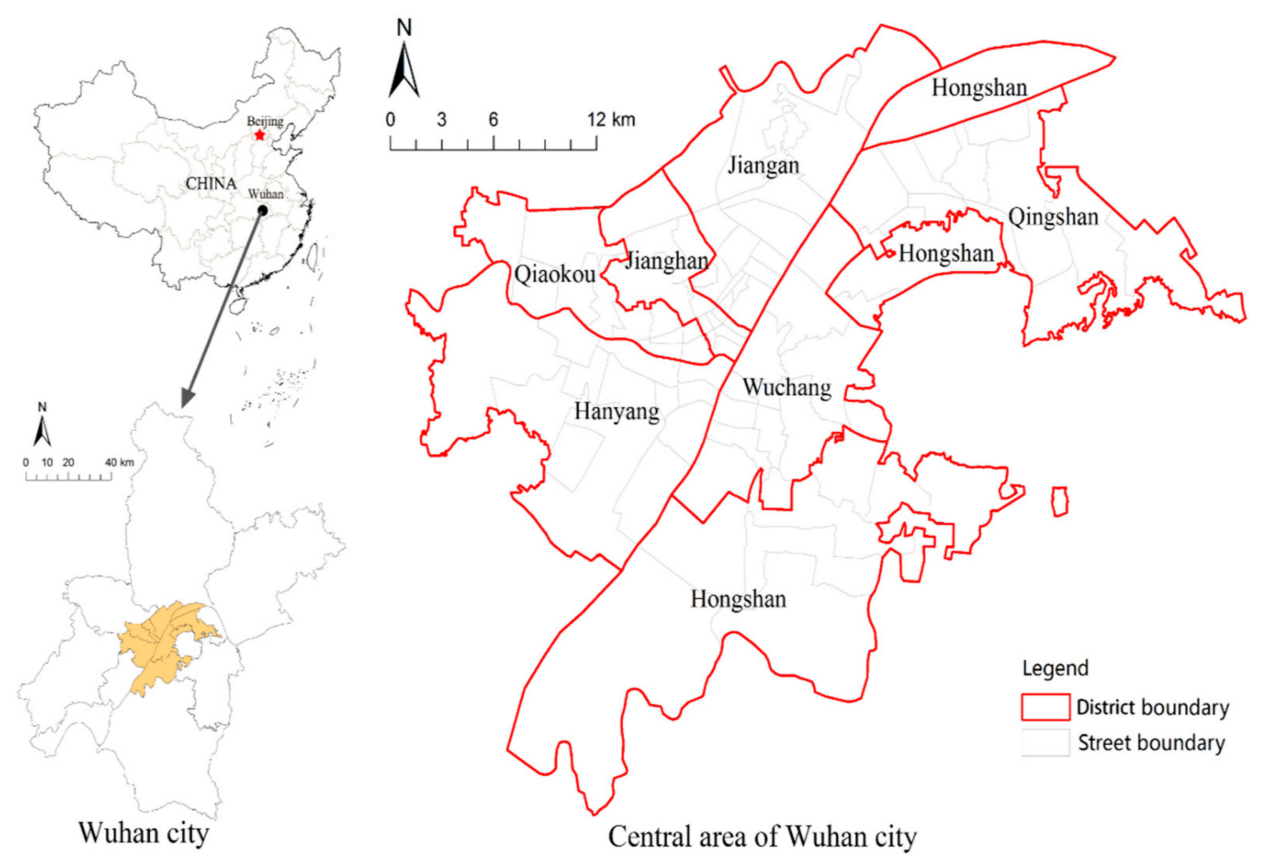

Figure 1. The location and administrative boundary of the study area.

2.2. Data Sources and Preprocessing

(1) The population data are also derived from the statistical yearbook of Wuhan in 2016 (the date of the statistics is at the end of 2015), and the corresponding population density distribution of the block (Figure 2) is generated based on the administrative division data, which are based on the vectorization of raster maps of each district.

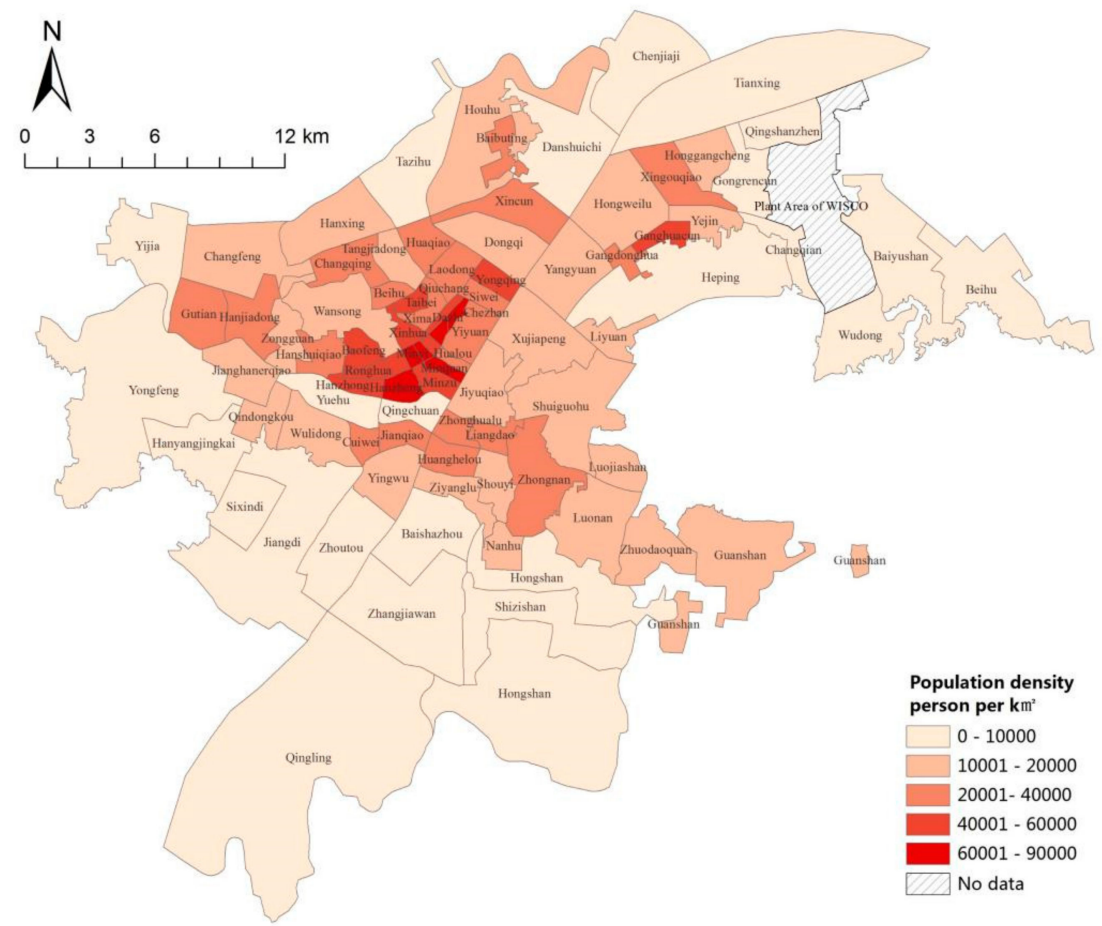

Figure 2. The street-level population density of the central area of Wuhan City in 2015. 
(2) The vector data of the green park (Figure 3a) required in this paper is derived from "the green space system planning of Wuhan", taking the "boundary effect" into account, which will also include green parks in a $1500 \mathrm{~m}$ range outside the edge of the study area. The data is corrected by comparing current and historical Google Earth images, and the park entrance and exit location are determined by Baidu Map.

(3) The road network data in the region is interpreted from high-resolution Remote Sensing Satellite images. As shown in (Figure 3b), vector road network data of the study area were constructed after checking the topology. This data was used in the 2016 "Sponge City Sponge City Special Plan for Wuhan (Sponge City Sponge City Special Plan for Wuhan. http://www.wpdi.cn/project3-i_11332.htm)", this is a joint official planning project held by Wuhan planning and design institute and Wuhan natural resources and planning bureau. The road vector data were provided by Wuhan planning and design institute.

(4) The land cover data (Figure 4) were interpreted by landsat8 remote sensing image, which was dated 5 June 2016. The image was downloaded from the website of the China Geospatial Data Cloud (http://www.gscloud.cn/). Firstly, ENVI5.3 tool is used to preprocess the image, such as through radiometric calibration, atmospheric correction, fusion, cutting, and so on. Then, the maximum likelihood method is used to supervise and classify the images, which are divided into seven categories: Woodland, farmland, water, road, bare land, factory buildings, and other paving. We use high-precision Worldview 2 remote sensing images of the Wuchang district (dated 29 July 2016, with $1.8 \mathrm{~m}$ multispectral and $0.5 \mathrm{~m}$ panchromatic resolution) as ground truth samples for the classification accuracy evaluation. Ten regions of interest (ROIs) of each type of land cover were selected as evaluation samples by visual interpretation. Finally, we evaluated the classification accuracy using the confusion matrix method, and the results showed that the overall accuracy was $83.4192 \%$ and the Kappa coefficient was 0.8040 .
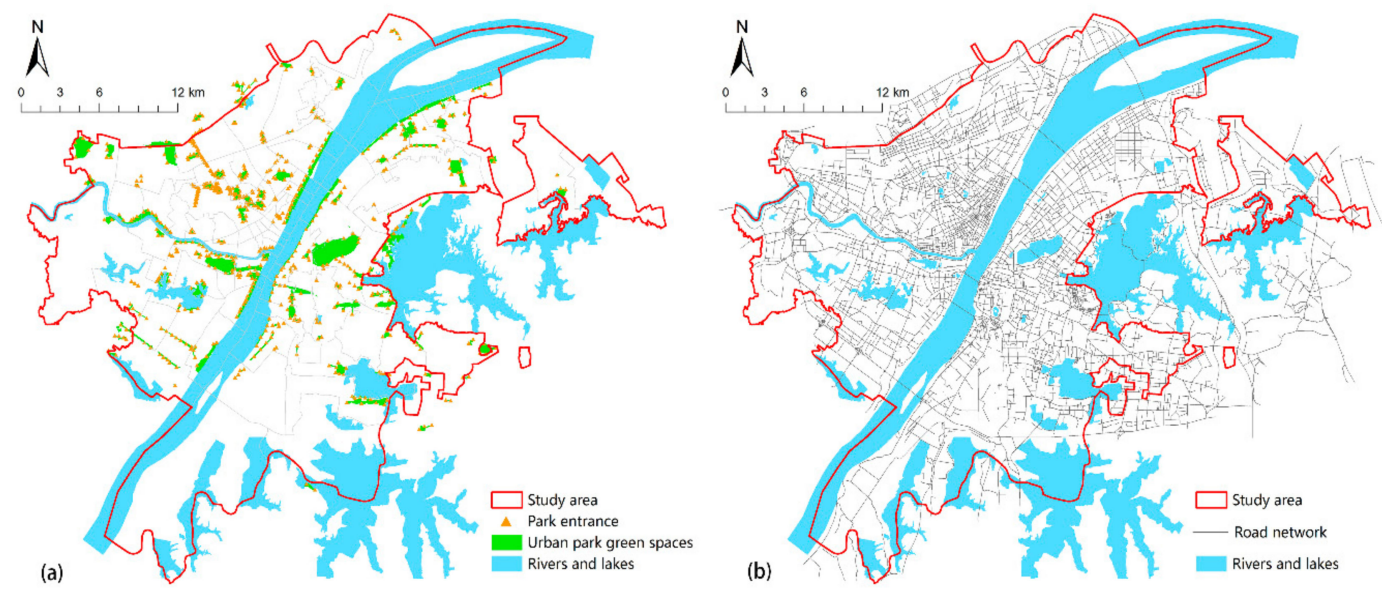

Figure 3. Urban park green space (a) and road network (b) in the central area of Wuhan City. 

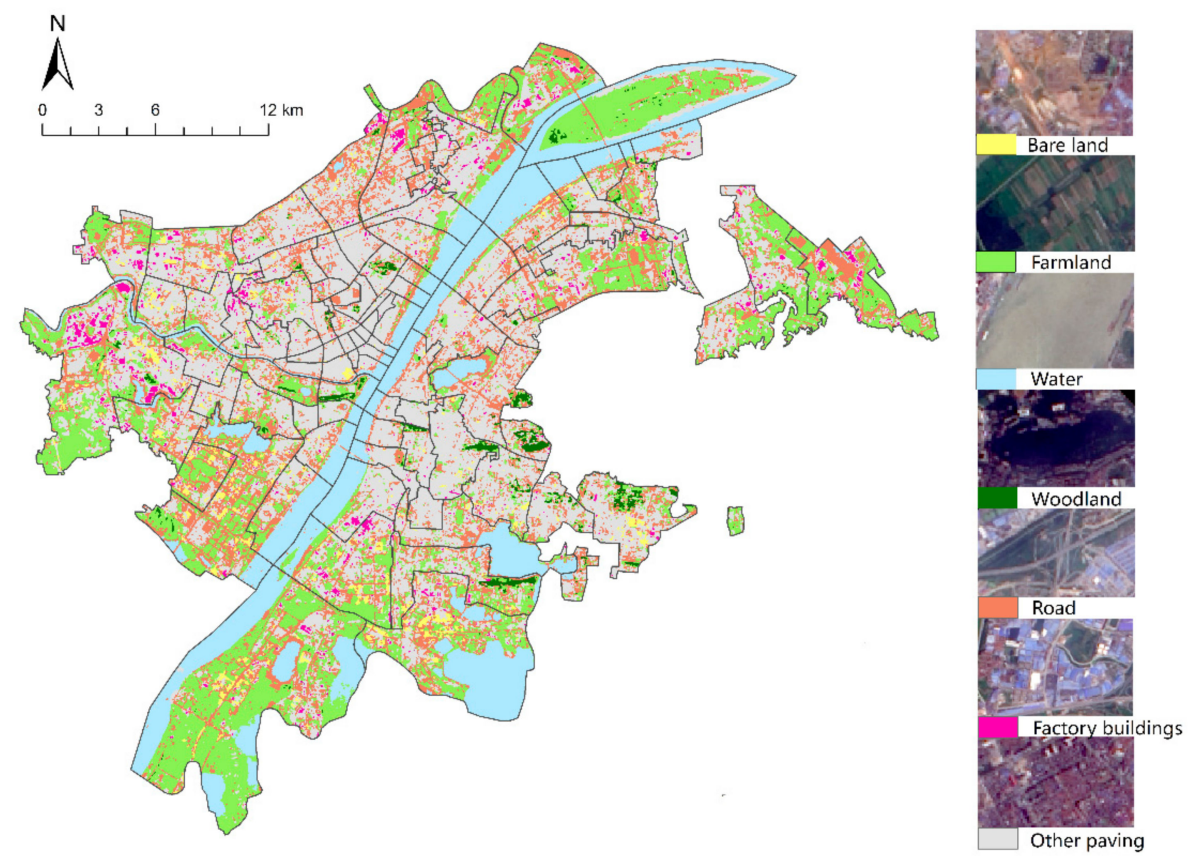

Figure 4. Land cover in the central area of Wuhan City.

\section{Methods}

\subsection{Population Data Spatialization}

The population data spatialization is based on the spatial distribution model of population and uses a certain calculation method to analyze the data and to present the implicit spatial information in order to simulate its geographical distribution. This method includes spatial interpolation [22], remote sensing spectral feature estimation [23], estimation model based on multi-source data [24-26], estimation model based on land use/land cover (LULC) [27], and so on. The theoretical basis of the spatial interpolation method is that the closer the spatial position is, the more likely it is to have similar eigenvalues. Thus, the statistical population based on administrative division is transformed into grid population data. The advantage of the interpolation method is that it is simple and feasible, and it can also eliminate the abrupt data on both sides of the administrative boundary line to a certain extent. The disadvantage is that only the conversion of the data presentation format is completed, and the ability to depict the real population distribution is weak [28]. The remote sensing spectral feature estimation method evaluates population distribution according to the relationship between remote sensing spectral characteristics and population data. Researchers such as Lo C. P. [29] studied the relationship between the gray value of thematic mapper (TM) images in different bands and urban population density. Because the population distribution is related to many factors, such as geographical location, land cover, road network convenience, water area, and economic development, etc. [19], some scholars have begun to use a variety of data as indicative factors related to population distribution. For example, Wang L. et al. [30] combined LULC data and night-light data and simulated the spatial distribution of population in China in 1990, 2000 and 2010. There are also many studies using point of interest (POI) data [31] and Volunteered Geographic Information (VGI) [32]. The estimation model based on LULC is the most widely used method for population spatial distribution simulation. The principle is based on establishing a multivariate statistical regression model based on LULC data and population distribution to estimate population distribution. However, due to the spatial heterogeneity of population distribution [33], compared with the Global Multivariate Statistical Regression model, the Geographical Weighted Regression (GWR) is more fitting to the performance of population distribution [34,35]. For example, Zhao Zhen et al. [35] used the GWR model to construct a spatial study of population data in southwest China. In this paper, by constructing a GWR model 
between LULC and demographic data, the regression coefficients are obtained to simulate the spatial distribution of population within the study area.

\subsubsection{Spatial Method of Population Data Based on Land Cover}

This method assumes the same population density for the same land cover type. Firstly, the land cover data is obtained by using remote sensing image interpretation; then, the land cover data unit is taken as the explanatory variable, and the multivariate regression model is constructed with demographic data as the cause variable. The formula is as follows:

$$
p_{i}=\sum_{j=1}^{n} a_{j} \times S_{i j}+b
$$

where $p_{i}$ is the statistical population of the $i$ th block in the study area, $a_{j}$ is the population distribution coefficient under the $j$ type land cover type, $S_{i j}$ is the area of the $j$ land cover type in the $i$ block, $n$ represents the number of land cover types. According to the principle of "no land without population", the constant $b$ is 0 .

According to Formula (1), we can simulate the predicted population value of each block, and then test the error according to the following formula:

$$
E=\frac{p_{i}^{\prime}-p_{i}}{p_{i}} \times 100 \%
$$

where $E$ is the relative error, $p_{i}$ is the actual population count of block $i$ in the study area, and $p_{i}^{\prime}$ is the predicted population in block $i$.

Since the model assumes that the distribution of population coefficients of the same land cover type is the same, there must be a deviation between the predicted population and the actual population. In order to ensure that the sum of the population data in the grid is consistent with the actual population sum, the adjustment method is used to revise the initial coefficients, and the process of rescaling is shown in the following equation:

$$
a_{i j}^{\prime}=\frac{p_{i}}{p_{i}^{\prime}} \times a_{j}
$$

where $a_{i j}^{\prime}$ is the population distribution coefficient under category $j$ of block $i$ after being amended, $p_{i}$ is the actual population count of block $i$ in the study area, and $p_{i}^{\prime}$ is the predicted population in block $i$.

A certain scale grid is constructed, and the land cover area in the grid is counted. On the basis of the correction coefficient, the population of the grid is inversely calculated to realize the rasterization of the population data. The grid demographics are shown in the following equation:

$$
\operatorname{pop}_{i j k}=\sum_{j=1}^{n} a_{i j}^{\prime} \times s_{i j k}
$$

where pop $_{i j k}$ is the population of the $k$ th grid cell, $a_{i j}^{\prime}$ is the correction of population distribution coefficient under category $j$ land cover type of block $i$, and $s_{i j k}$ is the area of the $j$ th land cover type on the $k$ grid cell in the $i$ block.

\subsubsection{Geographical Weighted Regression (GWR)}

In the geospatial analysis, the observed values of variables are generally obtained according to a given geographical unit as a sample unit, and with the change of geographical location, the relationship between variables will change, and the adjustment of the relationship between variables caused by the geographical location change is called spatial non-stationary adjustment. In order to solve the distortion of the analysis results caused by the non-smoothness of spatial data, the GWR model was 
proposed by Fotheringham on the basis of summarizing the previous studies on local regression and variable parameters [36]. The essence of the GWR model is to add a distance function as the weight on the basis of the traditional least squares method (OLS) regression model, so as to deal with the spatial non-stability of the data, and the related coefficients will change with the change of position. The model is in the following form:

$$
y_{i}=\beta_{0}\left(u_{i}, v_{i}\right)+\sum_{k=1}^{p} \beta_{k}\left(u_{i}, v_{i}\right) x_{i k}+\varepsilon_{i}
$$

where $\left(u_{i}, v_{i}\right)$ is the spatial coordinates of the sample point $i, \beta_{0}\left(u_{i}, v_{i}\right)$ is the intercept for location $I$, $\beta_{k}\left(u_{i}, v_{i}\right)$ is the local estimated coefficient of the independent variable $x_{j}$ at location $I$, and $\varepsilon_{i}$ is the error term.

In this paper, we use the ArcGIS10.2 GWR tool, taking demographic data as a dependent variable and land cover areas as independent variables. The adaptive method is used to calibrate the weighting function, and the optimal bandwidth is determined by the minimum Akaike information criterion (AIC).

The performance of OLS and GWR models was usually compared from two aspects: The predictive ability and the ability to address the spatial autocorrelation of variables [37,38]. We used the comparison model of the adjusted $\mathrm{R}^{2}$ and AIC. The higher the adjusted $\mathrm{R}^{2}$, the stronger the interpretation ability of variables, the smaller the AIC value, and the higher the fittest of the model. When the difference of the two models is greater than 3 , it is considered that the model with a smaller AIC value is better. The Global Moran's I index was calculated for the spatial autocorrelation; Moran's I values range from -1 to 1 . Values closer to 0 indicate that there is little or no spatial autocorrelation. If the Moran's I index value is regular, it indicates a clustered trend, and if the Moran's I index value is negative, it indicates a dispersed trend. If the distribution of the residuals obtained from the regression model has an obvious spatial autocorrelation, the assumption that residuals follow a random distribution is violated. That means the results of the model are not credible.

\subsection{Network Accessibility Analysis}

Network accessibility analysis is a method of calculating the service range of city parks under this cost value on the basis of a road network of the particular travel mode (by walking, cycling, bus or private car). Because it takes into account the actual routes and walking distances, network analysis can provide a more accurate measure of accessibility than using a simple buffering method $[39,40]$. A basic network consists mainly of centers, links, nodes, and cost. This study takes the real entrance and exit of the city park as the center, the city road as the link, while a node is an intersection between roads and the cost is expressed by the time spent on the road.

This study takes the time cost of residents walking to the park as a quantitative criterion for accessibility. With $1 \mathrm{~m} / \mathrm{s}$ as the average walking speed and knowing the length of the road, the cost value of each link can be calculated, and the intersection cost value is set to be $0.5 \mathrm{~min}$. According to people's travel habits, a maximum of $15 \mathrm{~min}$ to reach the green park is regarded as sound accessibility.

\subsection{Equity Evaluation}

On the basis of the population spatial and network accessibility analysis, spatial superposition analysis is used to generate a low-accessibility range of the population spatial distribution map and to count the low-accessibility population at the street scale; these are the overall indicators to measure the equity evaluation of urban green parks. 


\section{Results}

\subsection{Spatial Population Data Based on Land Cover Type}

\subsubsection{Performance Comparison of OLS and GWR Models}

There is a close relationship between population distribution and land cover type. Using LANDSAT8 remote sensing image data, this study classifies the study area, which is divided into 7 categories: woodland, farmland, water, road, bare land, factory buildings, and other paving. Taking the block as the unit to count the area of each land type as a variable parameter, and then using SPSS to carry out Spearman correlation analysis with the population number respectively, the regression model could be built, with the results (Table 1) showing that the population distribution was significantly correlated with bare land, road, vegetation, factories, and paving.

Table 1. Spearman correlation analysis between the population and land cover type.

\begin{tabular}{cccccccc}
\hline Land Cover Types & Bare Land & Road & Water & Woodland & Farmland & $\begin{array}{c}\text { Factory } \\
\text { Buildings }\end{array}$ & $\begin{array}{c}\text { Other } \\
\text { Paving }\end{array}$ \\
\hline Correlation coefficient & $0.387^{* *}$ & $0.229^{*}$ & -0.072 & $0.220^{*}$ & 0.111 & $0.279^{* *}$ & $0.529^{* *}$ \\
Significance level & 0.000 & 0.031 & 0.503 & 0.038 & 0.299 & 0.008 & 0.000 \\
\hline
\end{tabular}

${ }^{*}$ Correlation is significant at the 0.05 level; ${ }^{* *}$ Correlation is significant at the 0.01 level.

By combining various land type areas as explanatory variables, the population quantity is used as the dependent variable, and the OLS and GWR models are constructed. Finally, the model fitting optimization is best when road and other paving are used as explanatory variables. As can be seen from Table 2, variance inflation factor $(\mathrm{VIF})=1.97$, which is less than 7.5 , indicating that there is no multiple collinearity between variables. The AIC value of the OLS model is 515.417, and that of the GWR model is 458.706 . The adjusted $\mathrm{R}^{2}$ value of the GWR model is 0.78 , which is higher than that of the OLS model, at 0.34. As shown in Figure 5, the residual Moran's I of the OLS model is 0.04, the $\mathrm{z}$-score is 2.03 , and the $p$-value is 0.04 , indicating that the residual error of the OLS model shows an obvious clustered pattern, and the confidence level is 95\%. The Moran's I of the GWR model is 0.01 , the $\mathrm{z}$-score is 0.85 , the $p$-value is 0.39 , and the residual error of the GWR model is in random mode. The above factors showed that the GWR model was superior to the OLS model in all aspects.
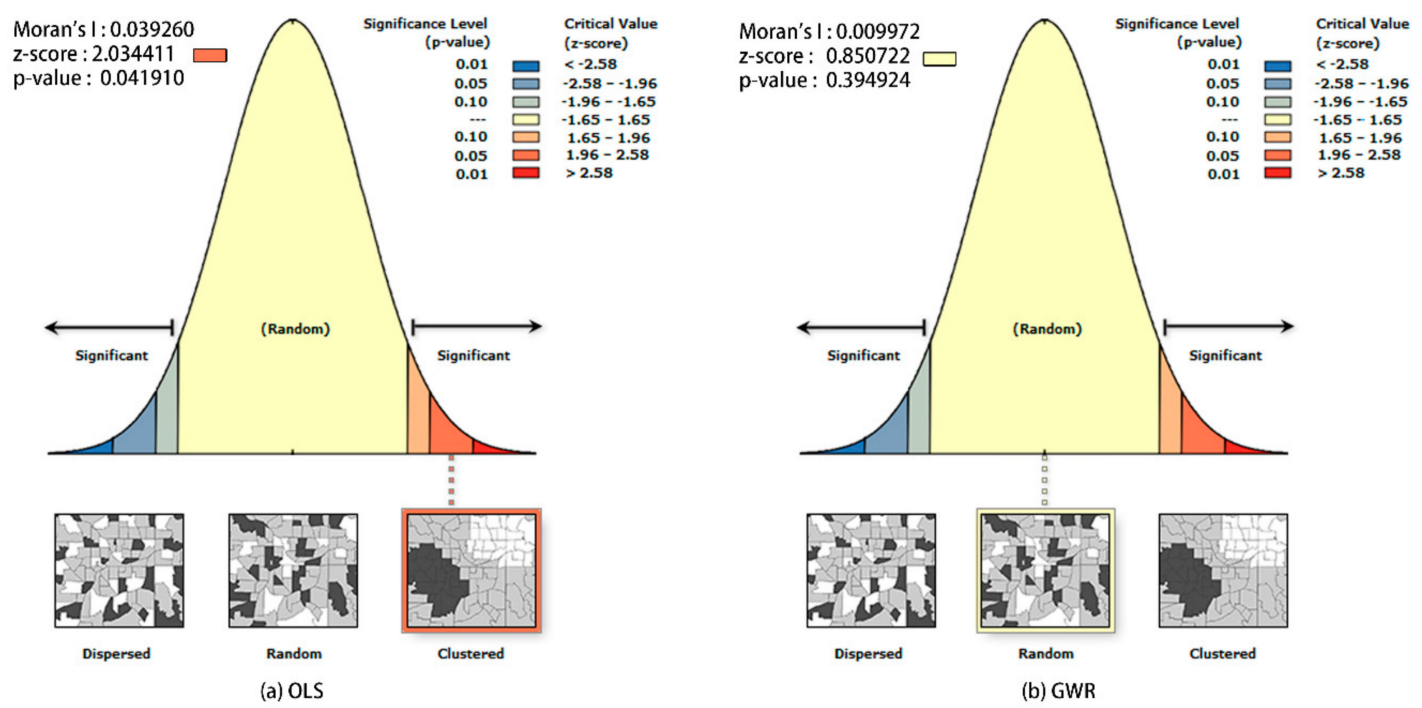

Figure 5. Comparison of Residual Moran's I index for traditional least squares method (OLS) (a) and global weighted regression (GWR) (b) models. 
Table 2. Comparison of OLS and GWR model results.

\begin{tabular}{cccc}
\hline & Model & OLS & GWR \\
\hline & VIF & \multicolumn{2}{c}{1.97 (Road) } \\
& & \multicolumn{1}{c}{ (Other paving) } \\
\hline \multirow{3}{*}{ Model parameter } & AIC & 515.417 & 458.706 \\
& $\mathrm{R}^{2}$ & 0.36 & 0.87 \\
& Adjusted R & 0.34 & 0.78 \\
& Moran's I & 0.04 & 0.01 \\
\hline
\end{tabular}

\subsubsection{Mapping the Population Spatial Distribution}

According to Formula 2, the population error of the model is tested. The total simulated population is 588,000, with an actual population of 576,000 and an overall relative error of $2.3 \%$. The results of the error evaluation on the block scale are shown in Table 3, with an average relative error of $35.8 \%$. Therefore, it is necessary to correct the error. On the basis of Formula 3, the corrected regression coefficient raster image can be obtained. In this study, $150 \mathrm{~m}$ was selected as the grid size, the road area and other paving grid images could be obtained by using the regional statistical tools, and the population spatial distribution of the $150 \mathrm{~m}$ grid (Figure 6) in the study area could be calculated by combining the corrected regression coefficient raster.

Table 3. The result of error evaluation on street scale.

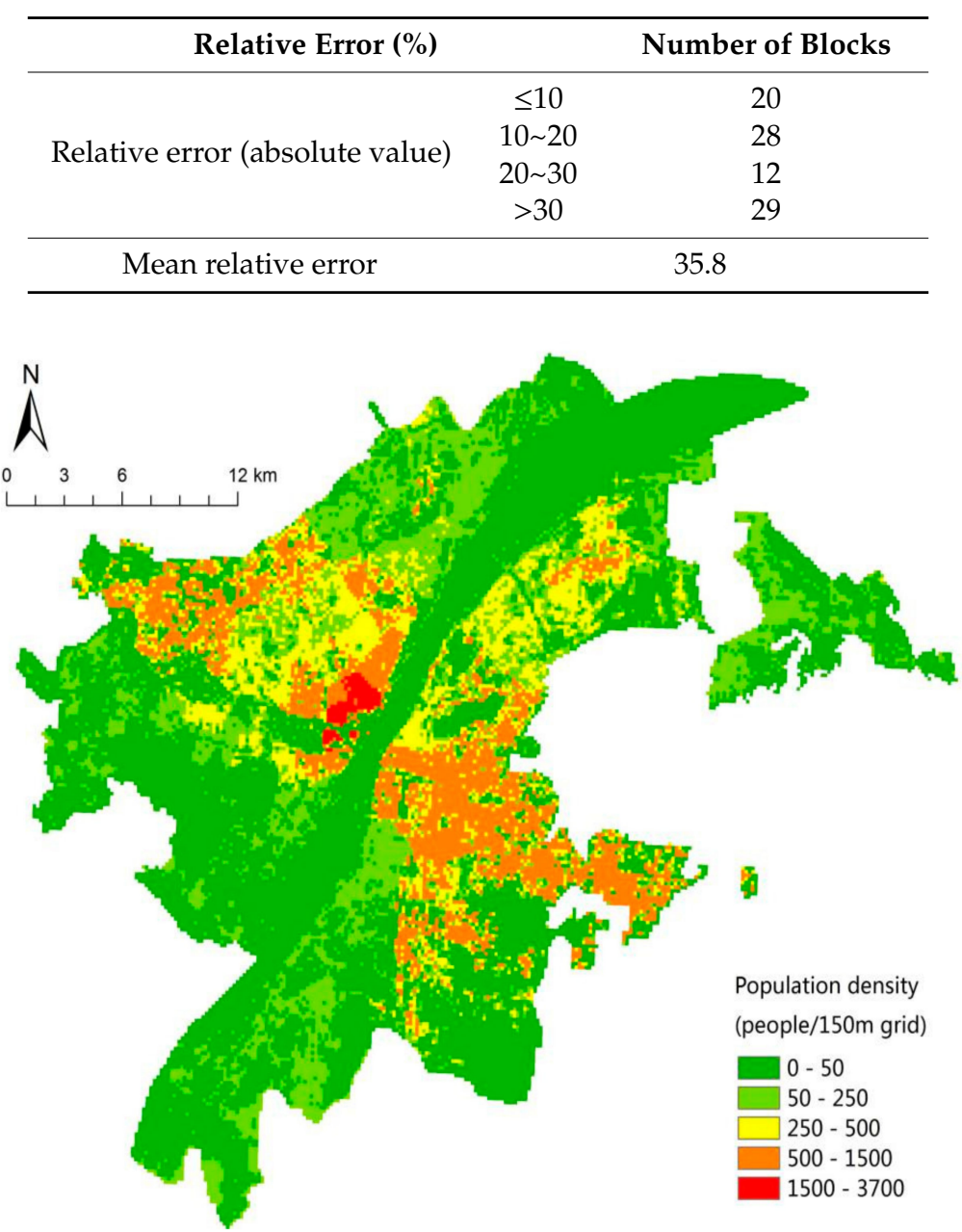

Figure 6. Spatialized population density map of Wuhan's central area in 2015. 


\subsection{Analysis of the Spatial Accessibility of Urban Park Green Spaces}

The accessibility analysis results of urban park green space based on network analysis are shown in Figure 7: the accessible coverage area, the area within a 15 min walking range of a park, reached $161.28 \mathrm{~km}^{2}$, accounting for $25.8 \%$ of the total study area. In terms of spatial structure, areas with a high degree of accessibility are mainly concentrated in urban centers, including the junction of Jianghan District and Jiang'an District; most of the streets of Wuchang District, Hanyang District, and Qingshan District along the river. The green space in such areas is not only concentrated, but also the road facilities are relatively well constructed.

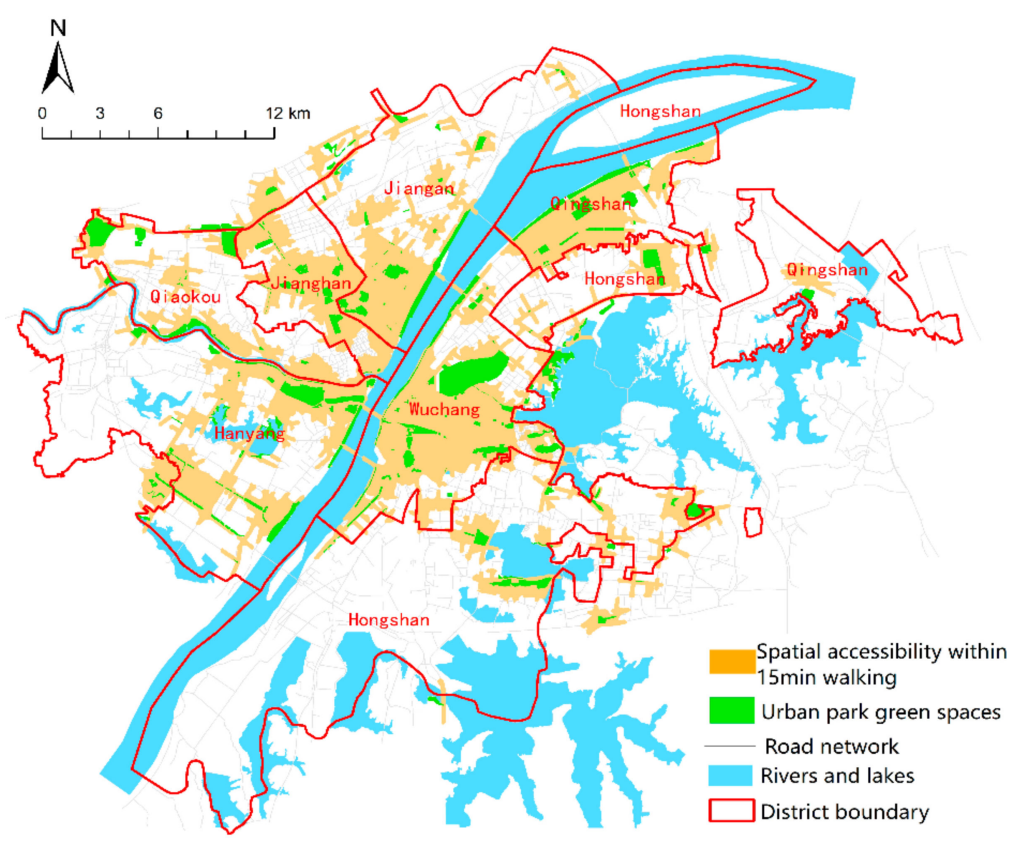

Figure 7. Service areas for urban park green space according to the network analysis methods.

The areas with poor accessibility are mostly concentrated in marginal areas, mainly due to the serious shortage of green space supply in the park. However, Jiangdi Street and Baishazhou Street in the southwestern part of the study area are less accessible due to the imperfect road system. That is, the density of the road network is low, and the supply of park green space is not the main reason for this.

\subsection{Evaluation of Green Space Equity in Urban Parks of Wuhan City}

Based on the analysis of the population spatial distribution and network accessibility, spatial superposition analysis is used to obtain the results of population spatial distribution with low-accessibility (Figure 8). Also, beyond the reach of $15 \mathrm{~min}$ on foot, Hanzheng Street of Qiaokou District, Minyi Street, and Qianjin Street of Jianghan District and other areas of the densest population distribution comprise up to 3617 people per $150 \mathrm{~m}$ grid—that is, 160,755 people per $\mathrm{km}^{2}$-which is well above the population density of 89,200 people based on street scale statistics per $\mathrm{km}^{2}$ (Figure 2). In addition, Yijia Street, Changfeng Street, Gutian Street, HanJiadun Street and Shizishan Street, Luonan Street, Zhuodaoquan Street, and Guanshan Street in the northwest of the city are densely populated.

According to statistics, the 15-min walking distance of Wuhan Central Park Green Space covers 3.1 million people, accounting for $54.2 \%$ of the total population. With streets as the basic unit, the total number of people outside the reach is counted, and the results (Figure 9) show that there are 12 streets at a level of equity, all of which are distributed in the center of the city. Most of these areas are close to comprehensive parks and green land along the river, with a population coverage of 100 percent. In general, except for Hanzheng Street, most of the unequal streets are located outside a 15 min walking distance, among which Hongshan Park has the worst equity. Three streets in Hongshan District are 
extremely unequal, namely Luonan Street, Shizishan Street, and Guanshan Street. Almost 220 thousand people on Guanshan Street are without accessibility. Hongshan District has many universities, such as Wuhan University, Huazhong University of Science and Technology, Central China Normal University, Huazhong Agricultural University, and so on. The dense distribution of colleges and universities makes the total population of the Hongshan area large. At the same time, Figure 7 also shows the scarcity of green space in the park, which leads to its inequity. In the future, Wuhan should give priority to the construction of park green space in Hongshan District to meet the recreation needs of its multitudinous users.

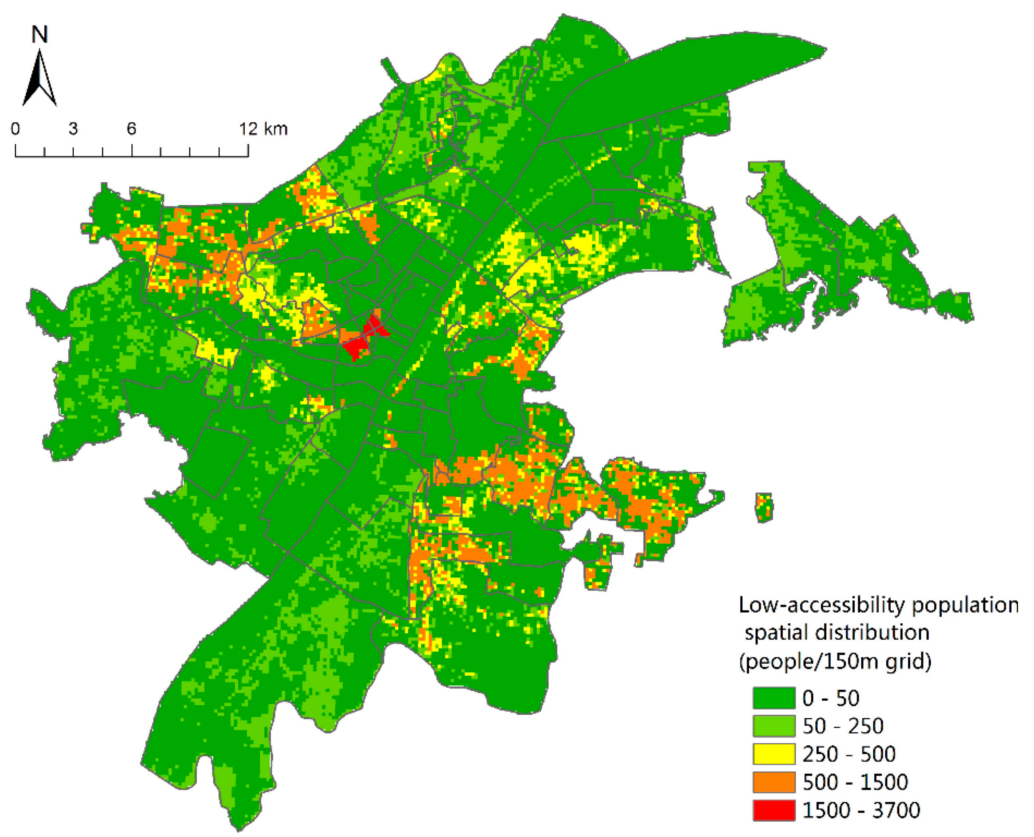

Figure 8. Low-accessibility population spatial distribution.

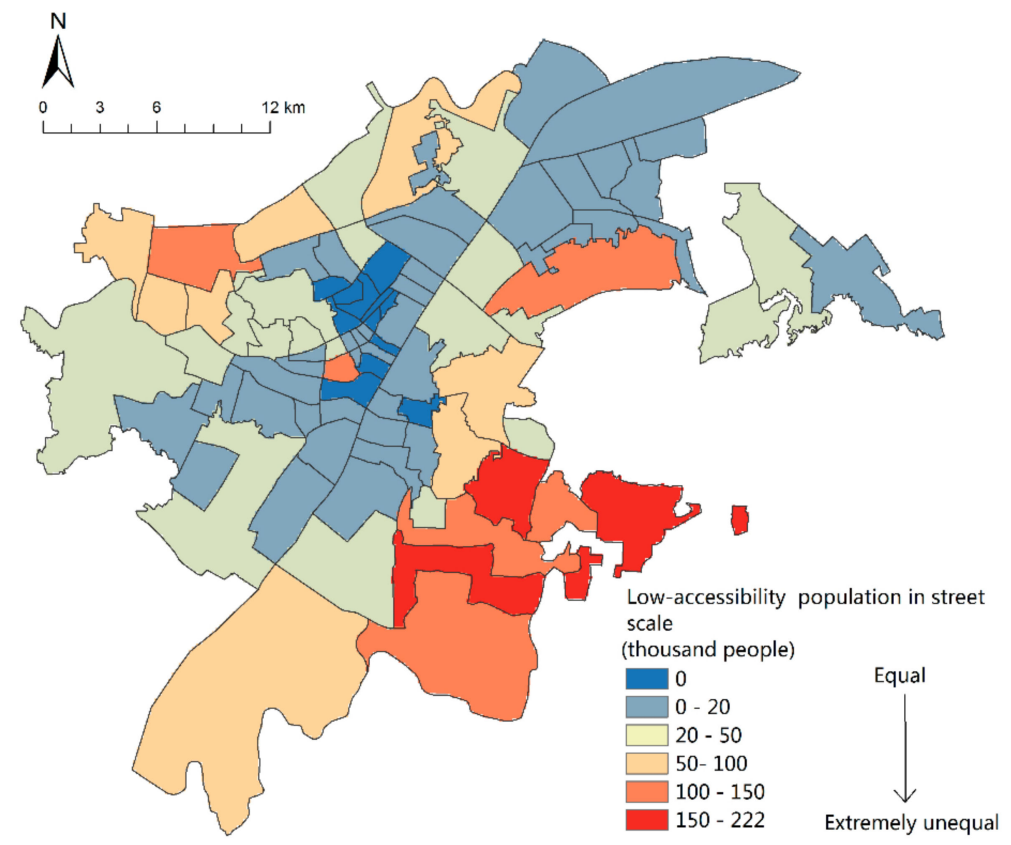

Figure 9. Low-accessibility population at the street scale. 


\section{Discussion and Conclusions}

Most of the current research on equity evaluation of green space in parks generally averages demographic data to measure the needs of users. For example, through the area ratio of the residential area and the street population data, the population of each residential area is counted and the spatial distribution of the population is calculated to evaluate the equity of the park green space [41]. There are some limitations in this method of assuming that the population is evenly distributed in residential buildings. On the basis of the study of the theory of the accessibility and equity of the green space of the park, this paper first adopted the population data spatialization method based on the land cover type to measure the demand level of the green space of the park and map the population data to the specific space unit. It is more accurate and more reliable than the traditional method (population data with the administrative division as the unit). Finally, the equity of park green space in the central city of Wuhan is evaluated quantitatively by adding the accessibility service range of park green space.

The evaluation results showed the range of park green space in the central urban area of Wuhan was within a walking distance of $15 \mathrm{~min}$, accounting for $25.8 \%$ of the total study area and, covering $54.2 \%$ of the population in the study area. In addition, areas with poor equity were mainly concentrated in the urban periphery due to the scarcity of park green space resources [42]. The equity of park green space in Hongshan District was the worst, so the government should focus on the allocation of park green space in this District in the near future.

However, there are still some limitations to this article. Since the vertical distribution (high-rise buildings) is also one of the important factors affecting the spatial distribution of the population, there have been studies to explore the method of spatializing population based on building information [19]. The building data of field visits are usually suitable for small-scale research, but it is difficult to obtain accurate building height information for the whole central area of Wuhan in our research. So obtaining such detailed vertical data and higher-resolution remote sensing images are the important aspects of our future efforts. In addition to the travel mode of walking, cycling or public transport could be added in the future to improve the results of the accessibility analysis.

At present, with the development of GIS technology, the evaluation method of park green space accessibility has become more and more mature, but quantifying the public demand has been a difficult problem in the relevant fields. This paper, based on the principle of equal sharing, takes the total population as a measure of demand and aims to provide a new method for quantitative demand space quantification.

In the future, other socio-economic data, such as the distribution of the elderly, children, or low-income groups, can be used to evaluate the needs of specific groups and include them under the existing landscape equity assessment system. The evaluation results will provide more effective support for the corresponding planning strategy. In addition, only considering the accessibility level, the fairness of urban park green space can be comprehensively evaluated in terms of per capita area and park quality in the future.

Author Contributions: C.T. performed the data collection and analysis, calibrated and validated the model. Y.T. formed the simulation works and performed the result interpretation. C.T. and Y.T. both finished writing the thesis. X.W. designed the concept and methodology and revised the manuscript. All authors made contributions to the study and to writing the manuscript.

Funding: This work was supported by the Fundamental Research Funds for the Central Universities (grant numbers 2662018JC042).

Conflicts of Interest: The authors declare no conflict of interest.

\section{References}

1. Heckert, M.; Christina, D.R. Developing a Green Infrastructure Equity Index to Promote Equity Planning. Urban For. Urban Green. 2016, 19, 263-270. [CrossRef]

2. Emmanuel, R.; Loconsole, A. Green Infrastructure as an Adaptation Approach to Tackling Urban Overheating in the Glasgow Clyde Valley Region, Uk. Landsc. Urban Plan. 2015, 138, 71-86. [CrossRef] 
3. Pataki, D.E.; Carreiro, M.M.; Cherrier, J.; Grulke, N.E.; Jennings, V.; Pincetl, S.; Pouyat, R.V.; Whitlow, T.H.; Zipperer, W.C. Coupling Biogeochemical Cycles in Urban Environments: Ecosystem Services, Green Solutions, and Misconceptions. Front. Ecol. Environ. 2011, 9, 27-36. [CrossRef]

4. McCormack, G.R.; Rock, M.; Swanson, K.; Burton, L.; Massolo, A. Physical Activity Patterns in Urban Neighbourhood Parks: Insights from a Multiple Case Study. BMC Public Health 2014, 14. [CrossRef]

5. Giuseppe, C.; Scopelliti, M.; Lafortezza, R.; Colangelo, G.; Ferrini, F.; Salbitano, F.; Agrimi, M.; Portoghesi, L.; Semenzato, P.; Sanesi, G. Go Greener, Feel Better? The Positive Effects of Biodiversity on the Well-Being of Individuals Visiting Urban and Peri-Urban Green Areas. Landsc. Urban Plan. 2015, 134, 221-228.

6. Kondo, M.C.; Fluehr, J.M.; McKeon, T.; Branas, C.C. Urban Green Space and Its Impact on Human Health. Int. J. Environ. Res. Public Health 2018, 15, 445. [CrossRef]

7. Kim, H.-S.; Lee, G.-E.; Lee, J.-S.; Choi, Y. Understanding the Local Impact of Urban Park Plans and Park Typology on Housing Price: A Case Study of the Busan Metropolitan Region, Korea. Landsc. Urban Plan. 2019, 184, 1-11. [CrossRef]

8. Tu, X.; Huang, G.; Wu, J. Review of the Relationship between Urban Greenspace Accessibility and Human Well-Being. Acta Ecol. Sin. 2019, 39, 421-431.

9. Dai, D. Racial/Ethnic and Socioeconomic Disparities in Urban Green Space Accessibility: Where to Intervene? Landsc. Urban Plan. 2011, 102, 234-244. [CrossRef]

10. Boone, C.G.; Buckley, G.L.; Grove, J.M.; Sister, C. Parks and People: An Environmental Justice Inquiry in Baltimore, Maryland. Ann. Assoc. Am. Geogr. 2009, 99, 767-787. [CrossRef]

11. Nicholls, S. Measuring the Accessibility and Equity of Public Parks: A Case Study Using Gis. Manag. Leis. 2001, 6, 201-219. [CrossRef]

12. Apparicio, P.; Abdelmajid, M.; Riva, M.; Shearmur, R. Comparing Alternative Approaches to Measuring the Geographical Accessibility of Urban Health Services: Distance Types and Aggregation-Error Issues. Int. J. Health Geogr. 2008, 7, 7. [CrossRef]

13. Luo, J.; Chen, G.; Li, C.; Xia, B.; Sun, X.; Chen, S. Use of an E2sfca Method to Measure and Analyse Spatial Accessibility to Medical Services for Elderly People in Wuhan, China. Int. J. Environ. Res. Public Health 2018, 15, 1503. [CrossRef]

14. Widener, M.J.; Farber, S.; Neutens, T.; Horner, M. Spatiotemporal Accessibility to Supermarkets Using Public Transit: An Interaction Potential Approach in Cincinnati, Ohio. J. Transport. Geogr. 2015, 42, 72-83. [CrossRef]

15. Smoyer-Tomic, K.E.; Hewko, J.N.; Hodgson, M.J. Spatial Accessibility and Equity of Playgrounds in Edmonton, Canada. Can. Geogr. 2010, 48, 287-302. [CrossRef]

16. Rigolon, A. A Complex Landscape of Inequity in Access to Urban Parks: A Literature Review. Landsc. Urban Plan. 2016, 153, 160-169. [CrossRef]

17. Lee, G.; Hong, I. Measuring Spatial Accessibility in the Context of Spatial Disparity between Demand and Supply of Urban Park Service. Landsc. Urban Plan. 2013, 119, 85-90. [CrossRef]

18. Openshaw, S.; Taylor, P.J. The Modifiable Areal Unit Problem. In Quantitative Geography: A British View; Wrigley, N., Bennett, R., Eds.; Routledge and Kegan Paul: London, UK, 1981; pp. 60-69.

19. Li, L.; Li, J.; Jiang, Z.; Zhao, L.; Zhao, P. Methods of Population Spatialization Based on the Classification Information of Buildings from China's First National Geoinformation Survey in Urban Area: A Case Study of Wuchang District, Wuhan City, China. Sensors 2018, 18, 2558. [CrossRef]

20. Dongrui, H.; Yang, X.; Cai, H.; Xu, X.; Qiao, Z.; Cheng, C.; Dong, N.; Huang, D.; Liu, A. Modelling Spatial Distribution of Fine-Scale Populations Based on Residential Properties. Int. J. Remote Sens. 2019, 40, 5287-5300.

21. Yang, X.; Wang, Z.; Li, Z.; Tang, Z. An Assessment of Urban Park Access in Shanghai-Implications for the Social Equity in Urban China. Landsc. Urban Plan. 2017, 157, 383-393.

22. Linard, C.; Gilbert, M.; Tatem, A.J. Assessing the Use of Global Land Cover Data for Guiding Large Area Population Distribution Modelling. GeoJournal 2011, 76, 525-538. [CrossRef]

23. Zeng, C.Q.; Zhou, Y.; Wang, S.X.; Yan, F.L.; Zhao, Q. Population Spatialization in China Based on Night-Time Imagery and Land Use Data. Int. J. Remote Sens. 2011, 32, 9599-9620. [CrossRef]

24. Briggs, D.J.; Gulliver, J.; Fecht, D.; Vienneau, D.M. Dasymetric Modelling of Small-Area Population Distribution Using Land Cover and Light Emissions Data. Remote Sens. Environ. 2007, 108, 451-466. [CrossRef] 
25. Yang, X.H.; Huang, Y.H.; Dong, P.L.; Jiang, D.; Liu, H.H. An Updating System for the Gridded Population Database of China Based on Remote Sensing, Gis and Spatial Database Technologies. Sensors 2009, 9, 1128-1140. [CrossRef]

26. An, H.; Xu, Y.; Sun, P.; Liu, C.; Zheng, W. Spatial Distribution of Population Specialization Based on Multi-Source Data: A Case Study of Zhangjiakou City. Resour. Sci. 2017, 39, 2186-2196.

27. Lo, C.P. Population Estimation Using Geographically Weighted Regression. Gisci. Remote Sens. 2008, 45, 131-148. [CrossRef]

28. Zhongqiang, B.; Wang, J.; Yang, F. Research Progress in Spatialization of Population Data. Prog. Geogr. 2013, 32, 1692-1702.

29. Lo, C.P. Application of Landsat Tm Data for Quality of Life Assessment in an Urban Environment. Comput. Environ. Urban Syst. 1997, 21, 259-267. [CrossRef]

30. Litao, W.; Wang, S.; Zhou, Y.; Liu, W.; Hou, Y.; Zhu, J.; Wang, F. Mapping Population Density in China between 1990 and 2010 Using Remote Sensing. Remote Sens. Environ. 2018, 210, 269-281.

31. Jin, C.; Zhang, X.; Huang, J.; Zhang, P. A Gridding Method of Redistributing Population Based on Pois. Geogr. Geo-Inf. Sci. 2018, 34, 83.

32. Yao, Y.; Liu, X.P.; Li, X.; Zhang, J.B.; Liang, Z.T.; Mai, K.; Zhang, Y.T. Mapping Fine-Scale Population Distributions at the Building Level by Integrating Multisource Geospatial Big Data. Int. J. Geogr. Inf. Sci. 2017, 31, 1220-1244. [CrossRef]

33. Xie, Y. Population Heterogeneity and Causal Inference. Proc. Natl. Acad. Sci. USA 2013, 110, 6262-6268. [CrossRef]

34. Kejing, W.; Cai, H.; Yang, X. Multiple Scale Spatialization of Demographic Data with Multi-Factor Linear Regression and Geographically Weighted Regression Models. Prog. Geogr. 2016, 35, 1494-1505.

35. Zhen, Z.; Xu, Z.; Hou, J. Application of Geographical Weighted Regression in Population Spatial Distribution Research. Remote Sens. Inf. 2018, 33, 128-134.

36. Fotheringham, A.S.; Charlton, M.; Brunsdon, C. Measuring Spatial Variations in Relationships with Geographically Weighted Regression, Recent Developments in Spatial Analysis; Springer: Berlin/Heidelberg, Germany, 1997.

37. Shiliang, S.; Li, D.; Hu, Y.; Xiao, R.; Zhang, Y. Spatially Non-Stationary Response of Ecosystem Service Value Changes to Urbanization in Shanghai, China. Ecol. Indic. 2014, 45, 332-339.

38. Huilei, L.; Peng, J.; Yanxu, L.; Yi'na, H. Urbanization Impact on Landscape Patterns in Beijing City, China: A Spatial Heterogeneity Perspective. Ecol. Indic. 2017, 82, 50-60.

39. Kshama, G.; Roy, A.; Luthra, K.; Maithani, S.; Mahavir. Gis Based Analysis for Assessing the Accessibility at Hierarchical Levels of Urban Green Spaces. Urban For. Urban Green. 2016, 18, 198-211.

40. Comber, A.; Brunsdon, C.; Green, E. Using a Gis-Based Network Analysis to Determine Urban Greenspace Accessibility for Different Ethnic and Religious Groups. Landsc. Urban Plan. 2008, 86, 103-114. [CrossRef]

41. Jiwei, X.; Fang, S.; Liu, C. Spatial Equity of Public Green in Wuhan Central Districts Based on Gravity Two-Step Floating Catchment Area Method. Resour. Sci. 2017, 39, 430-440.

42. Peilei, F.; Xu, L.; Yue, W.; Chen, J. Accessibility of Public Urban Green Space in an Urban Periphery: The Case of Shanghai. Landsc. Urban Plan. 2017, 165, 177-192.

(C) 2019 by the authors. Licensee MDPI, Basel, Switzerland. This article is an open access article distributed under the terms and conditions of the Creative Commons Attribution (CC BY) license (http://creativecommons.org/licenses/by/4.0/). 